\title{
"Electronic tongue" based on electrodes modified with polyarylenephthalides for recognition of model solutions of tryptophan
}

\author{
(C) Yulia A. Yarkaeva, ${ }^{+}$Elena V. Shestakova, Marat I. Nazyrov, \\ Rufina A. Zilberg, and Valery N. Maistrenko* \\ Department of Chemistry. Bashkir State University. Validy St., 32. Ufa, 450076. Russia. \\ Phone:+7 (347) 229-97-12. E-mail: julijajarkaeva05@gmail.com
}

\begin{abstract}
*Supervising author; ${ }^{+}$Corresponding author
Keywords: voltammetry, tryptophan, auxiliary substances, modified electrodes, electronic tongue, polyarylenephthalides, polyphthalidylidenefluorene, polyphthalidylidenediphenyl.
\end{abstract}

Abstract
The effect of auxiliary substances in the composition of the dosage form (sucrose, lactose, talc and starch) on the voltammetric registration of tryptophan using two- and threesensor systems such as "electronic tongue" based on glassy carbon electrodes modified with polyarylenephthalides was studied. For the subsequent chemometric processing of the obtained data, the principal component analysis and soft independent modeling of class analogies were used. It has been shown that electrodes modified with various polyarylenephthalides have cross-sensitivity to four model solutions of tryptophan, each of which contains a certain auxiliary component. When the modified electrodes are used separately, the analyzed model solutions of tryptophan form clusters on the score plots of PCA that intersect with each other, which does not allow them to be reliably recognized. However, the combination of modified electrodes into two- and three-sensor systems due to cross-sensitivity makes it possible to obtain the PCA score plots, in which clusters of samples of model solutions of tryptophan intersect less or do not intersect at all, and, therefore, to recognize them with a high probability. In almost all cases of using two- and three-sensor systems, the classification sensitivity is $100 \%$. When using modified electrodes separately, the specificity of the classification varies from 20 to $100 \%$, when using two-sensor systems - from 50 to $100 \%$. The specificity of the classification when using a threesensor system is not less than $90 \%$. The proposed sensor system, after additional studies, can be used to recognize medicines containing the same active substance, but different auxiliary components, and will also allow detecting the presence of impurities in medicines.

\section{References}

[1] H.K. Budnikov, G.A. Evtyugin, V.N. Maistrenko. Modified electrodes for voltammetry in chemistry, biology and medicine. Moscow: BINOM. Lab knowledge. 2010. 416p. (russian)

[2] V.N. Maistrenko, G.A. Evtyugin, A.V. Sidelnikov. Voltammetric electronic tongue. Analytical chemistry problems. Chemical sensors. Moscow: Nauka. 2011. Vol.14. 285p. (russian)

[3] E.A. Baldwin, J. Bai, A. Plotto, S. Dea. Electronic noses and tongues: applications for the food and pharmaceutical industries. Sensors. 2011. Vol.11. P.4744-4766.

[4] R.A. Zilberg, A.V. Sidelnikov, Yu.A. Yarkaeva, L.R. Kabirova, V.N. Maistrenko. Identification of bisoprololbased drugs using voltammetric "electronic tongue". Bulletin of the Bashkir University. 2017. Vol.22. No.2. P.356-362. (russian)

[5] A.V. Sidel'nikov, R.A. Zil'berg, Yu.A. Yarkaeva, V.N. Maistrenko, V.A. Kraikin. Voltammetric identification of antiarrhythmic medicines using principal component analysis. Journal of Analytical Chemistry. 2015. Vol.70. No.10. P.1261-1266.

[6] Yu.A. Yarkaeva, R.A. Zilberg, A.I. Khabletdinova, A.V. Sidelnikov, V.N. Maistrenko. Voltammetric identification of bisoprolol-based drugs using projection on latent structures. Bulletin of the Bashkir University. 2016. Vol.21. No.3. P.635-641. (russian)

[7] R.A. Zilberg, L.R. Kabirova, Yu.A. Yarkaeva, A.V. Sidelnikov, V.N. Maistrenko, V.M. Kornilov, A.N. Lachinov. Recognition of propranolol by manufacturer using glassy carbon electrodes modified with composites based on polyarylenephthalides, melamine and cyanuric acid. Proceedings of the RAS Ufa Scientific Centre. 2017. No.4. P.33-40. (russian) 
"ELECTRONIC TONGUE" BASED ON ELECTRODES MODIFIED WITH POLYARYLENEPHTHALIDES FOR...

[8] R.A. Zil'berg, Yu.A. Yarkaeva, E.I. Maksyutova, A.V. Sideln'ikov, V.N. Maistrenko. Voltammetric identification of insulin and its analogues using glassy carbon electrodes modified with polyarylenephthalides. Journal of Analytical Chemistry. 2017. Vol.72. No.4. P.402-409.

[9] R.A. Zilberg, Yu.A. Yarkaeva, D.I. Dubrovsky, A.I. Khabletdinova, and V.N. Maistrenko. Voltammetric "electronic tongue" for recognition of methionine-containing pharmaceuticals. Butlerov Communications. 2018. Vol.56. No.11. P.32-37. DOI: 10.37952/ROI-jbc-01/18-56-11-32

[10] Yu.A. Yarkaeva, D.I. Dubrovskii, R.A. Zil'berg, and V.N. Maistrenko. Voltammetric sensors and sensor system based on gold electrodes modified with polyarylenephthalides for cysteine recognition. Russian Journal of Electrochemistry. 2020. Vol.56. No.7. P.544-555.

[11] R.A. Zilberg, Yu.A. Yarkaeva, D.I. Dubrovsky, L.R. Zagitova, V.N. Maistrenko. Voltammetric multisensory system based on glassy carbon electrodes modified by polyarylenephthalides for the recognition and determination of warfarin. Analytics and Control. 2019. Vol. 23. No.4. P.546-556. (russian)

[12] L. Cole, P.R. Kramer. Human Physiology, Biochemistry and Basic Medicine. Chapter 1.4. Amino Acid Metabolism. Elsevier Science Publishing Co Inc. 2015. 248p.

[13] I.I. Krasnyuk, G.V. Mikhailova, T.V. Denisova, V.I. Sklyarenko. Pharmaceutical technology. Technology of dosage forms: textbook. Moscow: GEOTAR-Media. 2011. 656p. (russian)

[14] A.L. Pomerantsev. Chemometrics in Excel. New York: Wiley. 2014. 336p.

[15] R.G. Brereton. Chemometrics: Data Analysis for the Laboratory and Chemical Plant. Chichester: UK: Wiley. 2003.

[16] K.H. Esbensen. Multivariate analysis - in practice. Oslo: CAMO Process AS. 2001. 598 p.

[17] S.N. Salazkin, V.V. Shaposhnikova, L.N. Machulenko, N.G. Gileva, V.A. Kraikin, A.N. Lachinov. Synthesis of polyarylenephthalides prospective as smart polymers. Polym. Sci. A. 2008. Vol.50. P.243-259.

[18] N.G. Gileva, E.A. Sedova, T.A. Yangirov, S.N. Salazkin, V.A. Kraikin. Synthesis of 4-halogenated polyarylenephthalides. Bulletin of the Bashkir University. 2018. Vol.23. No.4. P.1001-1006. (russian)

[19] R.A. Zil'berg, V.N. Maistrenko, Yu.A. Yarkaeva, and D.I. Dubrovskii. An enantioselective voltammetric sensor system based on glassy carbon electrodes modified by polyarylenephthalide composites with $\alpha-$, $\beta$-, and $\gamma$-cyclodextrins for recognizing D- and L-tryptophans. Journal of Analytical Chemistry. 2019. Vol.74. No.12. P.1237-1247.

[20] O.E. Rodionova. Chemometric approach to the study of large amounts of chemical data. Russian chemical journal. 2006. Vol.1. No.2. P.128-144. (russian) 